\title{
¿REALIDAD DE LA FICCIÓN EVALUADORA O FICCIÓN DE LA REALIDAD EVALUADORA? APUNTES LITERARIOS Y CINEMATOGRÁFICOS PARA UNA CRÍTICA DE LA RAZÓN EVALUADORA
}

REALITY OF THE EVALUATING FICTION OR FICTION OF THE EVALUATING REALITY? LITERARY AND CINEMATOGRAPHIC NOTES FOR A CRITIQUE OF THE EVALUATIVE REASON

\author{
FACUNDO GIULIANO* \\ Universidad de Buenos Aires, Argentina. giulianofacundo@gmail.com
}

Recibido el 21 de MARZo de 2019, APROBADO El 17 dE JUNIO dE 2019

\begin{abstract}
RESUMEN
El presente ensayo parte de una pregunta que transita la frontera entre la realidad y la ficción de la evaluación e indaga el tipo de racionalidad específica que ella supone. Con esa idea, se toman como motivo para la reflexión producciones cinematográficas y literarias que posibilitan analizar críticamente algunas dimensiones de lo que entendemos por razón evaluadora. De este modo, se convida un bosquejo del antagonismo irreductible que divide el acto de educar de la obsesión por evaluar y traza ciertas coordenadas de lucha en el campo filosófico-educativo, al tiempo que se abren diferentes sentidos del deseo de enseñar y el lenguaje educativo. Como una ida al cine o al teatro, este ensayo plantea diferentes momentos en el abordaje del problema: una entrada o introducción; diferentes actuaciones del problema cinematografiado; un intervalo sobre la certeza del evaluar y la extrañeza del educar y telón, como final abierto por una excusa literaria.
\end{abstract}

\section{Palabras clave}

Filosofía de la educación, razón evaluadora, pedagogía, ética.

\begin{abstract}
This paper is based on a question that crosses the limits between reality and fiction of evaluation and looks into the type of specific rationality it implies. With this idea, cinematographic and literary productions are taken as a reason for reflection that make it possible to analyze critically some dimensions of what is understood as evaluative reason. In this way, a sketch of the irreducible antagonism that divides the act of educating from the obsession of evaluating, and traces certain coordinates of struggle in the philosophical-educational field while different meanings of the desire to teach and the educational language are opened. Like going to the cinema or the theater, this paper proposes different moments in the approach of the problem: an entrance or introduction; different performances of the problem; an interval, about the certainty of evaluating and the strangeness of educating; and a curtain, as an open ending for a literary excuse.
\end{abstract}

\section{KEY WORDS}

Philosophy of education, evaluative reason, pedagogy, ethics.

* (D) orcid.org/0000-0003-3404-1612 Google Scholar 


\section{Entrada: sobre minutos soberbios y una medida de la que nunca dispondremos (aunque la inventemos)}

Nietzsche en su conocido texto Sobre verdad y mentira en sentido extramoral describía el momento en que "animales astutos" inventaron el conocer como el minuto más soberbio y falaz de la historia. Allí señala que el intelecto como medio para la conservación desarrolla sus fuerzas primordiales en la ficción (que tiene como contracara de su arte al engaño y la mentira, la adulación y la murmuración, el fraude y la hipocresía, el vivir del brillo ajeno, el enmascaramiento o convencionalismo encubridor, el revoloteo incesante de la vanidad). Esto ha llegado al punto de generar un extraño y constante deseo de verdad: así, cuenta Nietzsche, se han inventado unas leyes de verdad mediante el poder legislativo del lenguaje que designa los criterios uniformes de validez que marcarán el contraste entre lo verdadero y lo falso. Pero del deseo de verdad a los criterios de validez que marcan a lo verdadero como tal, Nietzsche afirma un tercer punto que pone de manifiesto el hecho de que solamente mediante el olvido puede alguien alguna vez llegar a imaginarse que está en posesión de una verdad. Porque ya cuesta trabajo reconocer ante sí que el insecto o el pájaro perciben otro mundo completamente diferente y que la cuestión de cuál de las percepciones del mundo es la correcta carece totalmente de sentido, puesto que para decidir sobre ello tendríamos que medir con la medida de la percepción correcta, esto es, con una medida de la que no se dispone.

Como puede observarse, hoy que pareciera ser la época de la obsesión por la medida como valor, o de la neurosis por evaluar "cada vez más y mejor"; el mencionado texto nos brinda algunas coordenadas para entrar en este problema. Si el minuto más soberbio y falaz de la historia está dado por el momento en que "animales astutos" inventaron el conocer, ¿qué hay para decir de los minutos posteriores donde esos mismos animales se inventaron las ficciones subsiguientes? Podríamos decir que de la ficción del conocer devino la ficción de la evaluación del conocer, pues se establecieron los criterios que darían por válido un conocer veraz o un conocer falaz, asimismo se ha olvidado (no solo el sujeto de sí mismo) que no se dispone de una medida de la "percepción correcta", lo cual hace que -a partir de este olvido- pueda imaginarse que está en posesión de una verdad y vivir con cierta tranquilidad. Esto hasta que aparece la alteridad como relación de lo singular, lo no idéntico, lo que suele escaparse de toda clasificación, de toda rígida regularidad o de la lógica del rigor que hace de lo dicho, lo escrito y la voz un frío número a promediar entre otros. 
No obstante, esta aparición también enseña que la dureza puede ser versátil y siempre útil en su designio, aunque este nada tenga que ver con la verdad. Y así, una vez encuadrada en este terreno ya no hay posibilidad de contar otro cuento que no sea el que cuenta con precisión los puntos flacos y hondos del errar como negatividad, para luego ajustar la singularidad a la corrección del orden establecido en la escala jerárquica con que le toca lidiar. $\mathrm{Y}$ así, todas las miradas se concentran en sospechar de los demás: para corregirlos, identificar las faltas, ser impiadosos con los desvíos, perseguir lo que no se amolde y, de esta manera, se fabrica lo insuficiente, lo deficiente, lo eficiente, como datos que confirman, de centro a periferia, la normalidad. De esta forma la norma se erige como centro de gravedad y medida desde el/la cual se autoriza todo tipo de sospecha, desprecio y humillación. Y así, quizá la clave de todo radique finalmente en neutralizar la obligación de juzgar.

\title{
Actuaciones cinematográficas del problema. Distopías como presentes cercanos o la realidad también tiene estructura de ficción
}

\begin{abstract}
si por un lado la imaginación no desecha nada del fondo precedente, ni las reglas, ni los excesos sentimentales ni la experimentación, por el otro está atenta a (...) la existencia de los "mecanismos", empezando por la tecnología, siguiendo por la dominación económica y política y terminando por lo incidental de quienes podrían reconocerse en la representación que el arte intenta hacer de ellos. No es por azar el virtuosismo de los "efectos especiales" ni tampoco la ventaja que sobre las otras artes tiene el cine y su primo hermano la televisión. Noé Jitrik, Verde es toda teoría
\end{abstract}

\section{i. Cuando un tropezón es caída}

En el año 2016 la célebre serie Black Mirror estrenó el primer capítulo de la tercera temporada cuyo título fue traducido como "Caída en picada", allí se presenta un futuro en el que las redes sociales han permeado todos los aspectos de la vida cotidiana. En esta representación del mundo cada persona es calificada por sus publicaciones y formas de interacción con la gente. El mundo se mira a través de una óptica evaluadora permanente que permite visualizar la cifra que promedia los puntajes obtenidos por cada persona, esto es, el ciframiento de cada singularidad. Cada paso y encuentro con otros puede ser un tropezón que nos hace caer o un salto que nos eleva la puntuación haciéndonos subir o bajar respectivamente en la pirámide social. Por supuesto, tener 
un buen promedio de calificaciones nos convertirá en sujetos admirados y envidiables, así como una mala puntuación nos pondrá junto a los renegados y despreciados de la sociedad, es decir, sujetos de los que habrá que desconfiar como si fuéramos delincuentes condenados hasta que se compruebe lo contrario. La distancia de la brecha social se mide entre quienes están híper-valorados y quienes viven sub-valorados o por debajo del promedio establecido como "normal" o aceptable en la media. En este contexto, el número no solo influye en la manera que otros nos perciben sino que también determina los lugares donde se puede vivir, los trabajos a los que se puede aspirar, los lugares que se pueden visitar o el tipo de vehículo que se puede o no adquirir. Como la vida entera pende de una puntuación, las vidas giran en torno a las apariencias, a la obsesión neurótica por satisfacer al Otro al punto de llevar la corrección política a niveles extremos del comportamiento que van desde la exposición a incomodidades al auto-flagelo, con tal de mantener (o aumentar) el status y el número. De este modo, la irritación, el enojo, el desacuerdo, el desorden, la incorrección y toda pasión "negativa" que se manifieste puede ser motivo de una devaluación, con lo cual todas ellas tendrán que pasar necesariamente por el filtro superyoico de lo bello, ordenado y correcto, que determina la estética existencial dominante. Así, un dispositivo totalitario imposta el juicio como modo de vida que valora la falaz apariencia por sobre la verdadera opaca existencia del sujeto. La cohibición es regla en una sociedad obsesionada por la (buena) puntuación y el temor de dar una mala impresión. Como una evaluación final permanente, la seducción de lo impostado torna borrosos los límites entre lo verdadero y lo fingido.

Es conocido el refrán popular "sudaba como testigo falso", así como también la transpiración no del pensamiento -como decía Roberto Juarroz-, sino de estudiantes durante los exámenes. Pues estos deben exponerse y seducir hasta convencer a quien juzga de que poseen aquello que se espera que posean (una verdad aparente, un saber -siempre inaprensible como el deseo-, el dominio de un lenguaje que siempre se escapará) para no ser condenados y buscar la aprobación o eximición de la pena que toma forma de aplazo, suspenso, sanción. En contextos de evaluación permanente, la sinceridad no es una buena aliada para escalar en la pirámide social del promedio. Un contexto micro-político de esta envergadura no parece tan distópico cuando observamos a instituciones educativas hacer referencia a su calidad por la evaluación permanente de su sistema, o como cuando aparecen aplicaciones que permiten evaluar el trabajo de profesionales que desean estar expuestos a recibir un feedback 
en forma de notas y comentarios que, al mismo tiempo, construye su "credibilidad profesional" (o grandes empresas que usan esta tecnología para "motivar" a sus empleados); o, incluso, aplicaciones que puntúan ex amantes, amistades, conocidos, jefes, vecinos y quien desee ser evaluado. Este es uno de los vectores de la racionalidad evaluadora que constantemente busca dar con el consentimiento y el deseo del otro para evaluarlo (Giuliano, "Desnudar la razón evaluadora"). Esta es la razón evaluadora en una de sus máximas expresiones. Un mundo de mismidades que no se tocan, donde la popularidad es influencia y esta se encuentra determinada por un número de aprobaciones o seguidores/evaluadores. Como si a mayor exposición, mayor control sobre lo dicho, se pudiera ser un sujeto más valorado. Quizá Ser, sí, pero sin jamás meramente estar.

\section{ii. El examen como igualdad de oportunidades: la farsa de una premisa (nunca) igualitaria}

Hay una imagen pedagógica clásica en la que un docente les dice a sus estudiantes (representados a veces por un pájaro, un mono, un pingüino, un elefante, un pez en una pecera, una foca, un perro o, a veces, en algunas representaciones, un gato y también un caracol y un sapo): "Para que la evaluación -o selección - sea justa, todos realizarán la misma prueba: subirán a ese árbol". Algo similar parece querer decir el thriller británico de 2009 titulado Exam. El argumento se basa en la reunión de ocho candidatos rigurosamente testeados y seleccionados que, para trabajar en una de las compañías más grandes del mundo, deben pasar el examen final en un cuarto cerrado junto a un guardia armado, una hoja de papel en blanco para cada uno, una pregunta sin definir claramente-pero que deben buscar responder en un máximo de ochenta minutos- y unas normas, a saber: a) no estropear el papel, voluntaria o involuntariamente; b) no dirigirse al guardia ni al supervisor que los vigila desde fuera; c) no abandonar la habitación; d) responder a la pregunta no explicitada. Ciertamente, cada candidato/a representa algún estereotipo o "diferencia" reificada: entre quienes se someten al examen puede verse un morocho, un caucásico, un árabe, una asiática, una rubia, una morena, una castaña y un sujeto extrañamente indefinido al que deciden llamar "Sordo". Desde el principio se observa quien lleva la voz cantante, quien no confía en nadie, quien calla porque supuestamente sabe algo que los demás no, quien intenta la colaboración mutua. De aquí la intriga que se instala por saber quién conseguirá pasar el examen y hasta donde estará dispuesto a llevar su perspicacia interpretativa acerca de lo no-dicho en las reglas planteadas 
inicialmente. Se trata, entonces, de hasta dónde llegan las acciones de cada cual en función de lo que las normas explicitadas no dicen y de encontrar la pregunta adecuada como respuesta fundamental que garantizaría el éxito. El tiempo del Cronos comienza su cuenta regresiva, la tensión se instala y el silencio es el primer invitado entre quienes habitan la sala. Suena a cualquier escena familiar de evaluación o examinación que hemos vivenciado en nuestro paso por cualquiera de la instancias del sistema educativo: una consigna igual para todo el grupo, un mismo tiempo, una hoja en blanco y un dispositivo vigilante que hace aflorar todo tipo de manifestaciones individuales, competitivas, manipulativas, sexistas y/o racistas, en el marco de un proceso de selección de la mejor aptitud para un futuro reconocimiento. Dicho esquema opresivo parece ser la repetición de una escena sintomática en educación: todos se enfrentan a lo mismo durante el mismo tiempo, se instala una tabula rasa o "papel en blanco" que trae consigo cierta demanda que es "igual" para cada quien, no se permite dirigir preguntas o conversaciones a quienes son considerados "superiores" en dicho contexto. No hay singularidad que cuente, no hay pasado o memoria histórica, tan solo una demanda inserta en un tiempo cronológico y una promesa de reconocimiento elevada por un juicio determinante. Si se responde bien, acorde a lo esperado, el sujeto queda aprobado e incluido; si se responde mal, el sujeto comienza a ser asediado por la exclusión que puede acontecer en cualquier momento y, mientras tanto, llevar la marca de una cifra que lo infravalora.

Por ello, si la educación se reduce a un mero proceso de selección que deriva en un (o varias instancias de) examen final cuya superación promete reconocimiento y cada quien es sometido a esto en nombre de la igualdad de oportunidades, como hemos visto en el Maestro ignorante de Rancière, dicha situación no hace sino aplazar la igualdad al infinito. Pues la idea de igualdad de oportunidades, con la que se disfrazan los discursos conservadores y progresistas defensores de la razón evaluadora, no es más que "una regla institucional que separa los criterios discriminadores operantes en el encuentro de grupos o categorías tradicionalmente desfavorecidas", como dijo Rancière en una conversación reciente (Giuliano, Rebeliones éticas 213). En contraposición, la igualdad de las inteligencias de la que habla Rancière (Giuliano, Rebeliones éticas 214) es un axioma que se plantea y nos esforzamos en verificar; no dice: todos los estudiantes son iguales sean blancos o negros, masculinos o femeninos, etc., solo demanda a quienes se dirigen a esos estudiantes hacerlo según la presuposición de que tienen la misma inteligencia que ellos/as. Desde esta perspectiva, el examen es un aspecto más de 
la lógica desigualitaria constitutiva de la razón evaluadora y no queda más que luchar contra ella.

\section{iii. III. Esa peligrosa mujer llamada divergencia, o de cómo no hay acontecimiento sin diferencia, insurgencia y lealtad}

Divergente, Insurgente y Leal es una popular trilogía de ciencia ficción escrita por Verónica Roth, que también fue adaptada al cine con cierto éxito. Esta distopía encarna una forma de lo que Deleuze anticipaba con el término sociedades de control, pues en una futurista ciudad se ha determinado organizar la sociedad en agrupamientos de personas según cinco facciones que tratan de erradicar los males que les llevaron a la guerra. Quienes culpaban a la agresividad, crearon la facción Cordialidad; quienes culpaban a la ignorancia, se agruparon en la facción Erudición; contra el engaño, surgió la facción Verdad; contra el egoísmo, Abnegación; y contra la cobardía, surgió la facción Osadía. Llegada cierta edad (16 años), cada sujeto debe tomar la decisión de permanecer en la facción de sus padres o cambiarse de ella. Si se optaba por esta última opción, el sujeto tendría que renunciar a volver a ver a su familia. Tras la "ceremonia de elección", cada aspirante debe pasar por un proceso de iniciación -o selección- en cada facción: quien no lo supere se quedaría sin facción, convirtiéndose en paria. La prueba (de aptitud) consiste en una simulación que se desarrolla a través de la inyección de un líquido alucinógeno que expone a los sujetos en su mente a situaciones límites donde tendrían que poner en juego destrezas propias de su facción. El sistema funciona con éxito hasta que una joven descubre que es capaz de manipular las simulaciones y tomar decisiones prohibidas, lo cual hará que descubra que ella es una Divergente (persona capaz de manipular las simulaciones) y que tiene aptitud igual para facciones diferentes pero no encaja de lleno en ninguna de ellas. El dato curioso es la oda a la competencia que se encuentra en el mandato de "ganarse el lugar" entre sus compañeros y lo que caracteriza al Divergente: un sujeto capaz de pensar en forma independiente y que, al no poder ser controlado por el gobierno, se considera una amenaza al orden social existente. Agregamos: un sujeto que ha superado el propósito clasificatorio del dispositivo evaluador que rige la sociedad.

El panorama se agrava aún más en la segunda parte de la saga, Insurgente, cuando los conflictos generadores se extienden por las facciones; la joven divergente se enfrenta ahora a los dilemas propios de conflictos semejantes: la pena y el perdón, la identidad y la lealtad, la 
política y el amor. Cada facción se enfrenta a otra y el conflicto ideológico se pone sobre el tapete, la política deviene guerra que se edifica sobre la diferencia convertida en antagonismo radical y el amor un cuidado del otro que versa entre la pena y la culpa. Lo indecidible aparece aquí como un elemento que permite a la protagonista abrazar su diferencia para poner en juego el coraje de su verdad y la lealtad al acontecimiento que significa su intervención existencial. Esta lealtad se manifiesta en la fidelidad a una causa que diverge de una sociedad en la que cada facción desempeña su rol crítico en el mantenimiento del orden: así la diferencia es alteridad y la alteridad se torna un peligro para lo establecido.

Esta trilogía que comienza con el sometimiento de cada quien a una prueba, nos muestra que el problema de una sociedad basada en el control, que pone en juego lógicas que involucran a una racionalidad primordialmente evaluadora, no solo se trata de un dispositivo en el que habría que intentar neutralizar sus cuotas de nerviosismo o terror para sus participantes (como creerían algunos técnicos o especialistas del tema), sino que en su funcionamiento hay toda una gubernamentalidad que estructura la sociedad a partir de ello. Pues el principio de supervivencia social se establece como un reclamo que cualquiera tendría que realizar sobre el lugar que merece y el cual se establece mediante una prueba que dictaminará quién es cada cual realmente y qué merecerá. De este modo, se instala la noción de que el futuro pertenece solo a quienes saben a donde pertenecen y pueden probarlo. Por esto es que un resultado in-conclusivo en la prueba, que no dé certeza sobre "el lugar merecido", un resultado que no haga del examen una medición determinante, que no haga de la singularidad un significante de letra o número que la determine, es una prueba fallida o un error excluyente. La cuestión estará en ajustar la diferencia, clasificar la singularidad, vigilar las desviaciones y marginar a lo que no encaja. Esto último ha tenido diversas figuras en la historia del castigo (desde exclusiones donde el cuerpo padecía externamente su flagelo, hasta nuevos modos de introyección de la pena mediante aplazossuspensos $\mathrm{u}$ otras formas de descalificación que marcan al sujeto desde dentro hacia fuera). Así es que lo alteritario estuvo destinado a esconderse, a resistir la vigilancia normalizadora para poder re-existir. La razón evaluadora, que hace devenir a los sujetos en meras cosas a controlar su calidad en tal o cual desempeño, es la gubernamentalidad de las sociedades de control que habrá que resistir. Como dice uno de los protagonistas de la saga: "No quiero ser una cosa..." y de que no seamos meras cosas, depende nuestro mero estar (colectivo) como 
animales-humanos que se hacen sujetos en una insurgencia pedagógica que reclama siempre una fidelidad ineludiblemente infiel.

\section{iv. Cada quien crea su propio mérito (o fracaso)}

Someter las partes a un todo podría sonar a un principio comunitario pseudo-gestáltico. Pero la razón evaluadora cumple el mismo cometido en la educación moderna cuando cimienta, naturaliza o normaliza que no hay educación sin evaluación de las partes. Así, la evaluación deviene del artificio mediante el cual un tipo de racionalidad instituye que educar va de la mano con la lógica de la valoración como medición, clasificación, competencia y normalización como posibilidad de inclusión-exclusión. No habría inconsistencias que escapen de esta máquina de impostura, el todo estaría dado por un dispositivo que involucra dimensiones espaciotemporales claras y distintas. Ante esto, pensar esta problemática con Laclau nos permitiría visualizar que una radicalización de la educación podría aspirar a preservar el carácter conflictivo de todos los procesos sociales que involucra si pretende evitar convertirse en un sistema totalitario. "Construir sobre inconsistencias", parafraseando al poeta alemán Paul Celán, podría ser el principal camino de resistencia de una educación radical para la re-existencia.

Pensar al sujeto de la educación en clave moderna es pensar el sujeto de una potencial (d)evaluación, el Sujeto de una norma sin excepción. Butler ha enseñado que el sujeto se constituye de manera performativa, esto es, mediante una convocación reiterativa o "interpelación" que continuamente exhorta al sujeto a que se adhiera a una norma, pero esto no ocurre sin desviaciones ya que no todos los esfuerzos y secuencias de interpelación tienen un éxito total. Si la diferenciación implica un antagonismo, y ninguna exclusión se basa en la "naturaleza de las cosas" o puede al fin de cuentas justificarse, ninguna política puede lograr una forma final y ninguna exclusión puede ser definitiva.

En el intercambio epistolar que mantienen Judith Butler y Ernesto Laclau en torno a los usos de la igualdad, Butler sostiene que el fracaso de cualquier formación de sujeto es un efecto de su iterabilidad, de tener que formarse en el tiempo una y otra vez, lo que supone cierta susceptibilidad de un cambio de rumbo o un lapso en virtud de dicha necesidad de repetirse y reinstalarse. De allí su pregunta por el fracaso como condición para la formación del sujeto y una ampliación de la indagación al respecto: 
En la medida en que, independientemente de nuestra «diferencia», siempre estamos constituidos solo parcialmente como nosotros mismos (y esto, como resultado de que estamos constituidos dentro de un campo de diferenciaciones), ¿en qué medida también estamos ligados por este «fracaso»? ¿Cómo se convierte, extrañamente, la limitación de la constitución del sujeto en una nueva fuente de comunidad o colectividad o una supuesta condición de universalidad? (Butler \& Laclau 127)

Una respuesta tal vez podemos hallarla en los momentos de ruptura, rearticulación, convergencia y resistencia que no son cooptados de inmediato por las formaciones sociales (que, por otra parte, no pueden durar sin ser reinstaladas aunque corran el riesgo de deshacerse). A este respecto, un interesante ejemplo lo podríamos ver en la serie brasilera $3 \%$ cuya distopía muestra con creces una profunda brecha social en la que de un lado (llamado el Continente) se vive en una situación de pobreza con la población dejada a su suerte y en el llamado Otro Lado (aunque también Mar Alto, incluso se ha traducido en algunos países como la Costa o el Extranjero) se pinta un paraíso sin conflicto donde todo parece estar controlado y regulado con una alta calidad de vida destinada para el 3\% de quienes pasen anualmente El Proceso. Nuevamente retorna el argumento de la igualdad de oportunidades y el supervivencia del más apto: llegada cierta edad, cada habitante del Continente tiene la posibilidad de participar del Proceso para pasar al Otro lado que promete una vida mejor. Para ello, pasar el Proceso implica atravesar un sistema de pruebas donde los aspirantes deberán saber cuándo colaborar y cuándo competir entre sí. Además de mostrar claramente la falacia del argumento liberal de la igualdad de oportunidades, el planteo lleva a la pregunta límite de qué sería capaz de hacer cada quien con tal de formar parte de una elite privilegiada. De este modo, el antagonismo político se plantea entre quienes están a favor del proceso y orientan su vida a ello, a modo de cierta servidumbre voluntaria, y quienes buscan neutralizarlo en pos de una sociedad más igualitaria ${ }^{1}$. Ahora bien, en el caso de que algún candidato/a supere las pruebas y pase al Otro Lado,

\footnotetext{
${ }^{1}$ En el mencionado intercambio con Butler, Ernesto Laclau realiza un señalamiento importante respecto de la igualdad: pues decir que dos cosas son iguales -es decir, semejantes una con otra en algunos aspectos- presupone que son diferentes una de otra en otros aspectos, de lo contrario no habría igualdad sino mera identidad. Por ello, políticamente la igualdad es un tipo de discurso que intenta organizar las diferencias $y$, a partir de esto, es necesario subrayar las situaciones en que se da una política anti-igualitaria mediante la imposición de un canon dominante y uniforme (Butler \& Laclau 120).
} 
se cancela todo vínculo con su familia y entorno previo al reclutamiento, lo cual incluso llega a ser usado como argumentos en pruebas para garantizar de que el/la aspirante esté realmente convencido del cambio al que apunta. Una vez más los artilugios argumentativos de la razón evaluadora son puestos en escena: la auto-responsabilización (como auto-culpabilización en caso de fracaso) por el resultado obtenido, la obsesión por los mejores resultados y la estigmatización del error, la medición, comparación, clasificación, competencia y normalización de las singularidades. Aunque tal vez lo más impresionante por su eficacia simbólica sea el lema promovido durante el Proceso: cada uno crea su propio mérito (y, por lo tanto, su propio fracaso). Nada más rotundamente tramposo que este enunciado, y tal vez la serie sea la mejor prueba de ello, pero lo cierto es que, como la tan festejada y progresista evaluación por proceso que podría enarbolarse a partir del mismo lema, los términos del proceso ya están impuestos de antemano y la singularidad de cada quien deberá cifrarse y escalar partiendo del Uno (de un sí mismo que solo cuenta con la posibilidad de tornarse transparente al sistema y responder obsesiva, incluso, creativamente a todos sus requerimientos, o de resistir para buscar nuevos modos de re-existencia que bloqueen el dispositivo). Esto, ciertamente, nos encuentra más cerca de la causa de quienes no estamos con el proceso evaluador que sustenta el orden "natural" de las cosas y busca incansablemente el consentimiento del otro para hacerlo cómplice de su propia abyección ${ }^{2}$.

\section{Intervalo. El lenguaje infectado de la razón evaluadora y lo in(e)valuable del educar: de la profesión evaluadora a la extrañeza educadora}

Carlos Skliar en su reciente libro Pedagogías de las diferencias pone el cuerpo para mostrar, manifestar y convidar un cambio de voz en varios planos que denotan un antagonismo irreductible en medio de la lengua educativa: una lengua que comienza materna (por la infancia, el juego, el canto, la narración, las percepciones, la invención, el ritmo) y enseguida se convierte en una lengua paterna (por el patrón, las reglas, la gramática, la ley), una lengua que comienza abierta al tiempo libre o

\footnotetext{
${ }^{2}$ Esto puede observarse en uno de los episodios de la mencionada serie, donde uno de los protagonistas es convocado a inventar o formular una prueba para mejorar el proceso de selección, la cual, tiempo más tarde, sería utilizada sobre él mismo y lo dejaría eliminado del Proceso. Este cinismo propio de la razón evaluadora, es el mismo con que el funciona su lógica cruel de reconocimiento: en otro episodio puede observarse el festejo de quienes han pasado las pruebas y al director del Proceso diciendo "ustedes son gente de verdad".
} 
está liberada del utilitarismo y a la que se fuerza o tuerce a una lengua del trabajo, de la tarea, de la mercancía, del consumo; una lengua que pronuncia la reconstrucción de su memoria educativa en términos de gestos, roces, voces, rostros, textos y que luego se proyecta impune, casi sin cuerpo, como expresión acabada de una autoridad inmune sumida en la planificación y la evaluación, esto es, la mutación de un lenguaje propio del deseo de enseñar hacia un lenguaje infectado por la razón evaluadora (Skliar 14). Y este tipo de racionalidad, como ya hemos dicho, opera midiendo, comparando, normalizando, naturalizando, aunque sobre todo re-negando de lo que se le presente como raro, extraño, inexplicable según sus parámetros predefinidos que, de cualquier modo, buscarán algún tipo de reducción de aquello que altera el orden establecido.

Por lo tanto, somos testigos de dicha infección cuando vemos el ensañamiento con la fragilidad de cualquiera, una violencia arrojada contra la posición de indefensión, cuando advertimos ese doble juego inclemente de la impunidad -para decir y hacer cualquier cosa en nombre de la "normalidad", a favor de ella, de sus laberintos y tiraníasy de la inmunidad -en relación a un otro cuyos gestos parecen no afectar ni percibirse- (Skliar 26); cuando el deseo de enseñar se transforma en profesión del evaluar y aprender se reduce a un mero superar ciertos rituales o gestualidades de la humillación -como el ser juzgado o despreciado- y de la indiferencia -como la simulación de la farsa o la disimulación del dolor del mundo-.

Por lo tanto, el lenguaje del deseo de enseñar, la lengua de la educación, están más atravesados por lo extraño, lo raro (o queer), lo inexplicable, lo in-e-valuable, lo excitable, que por todo lo que supone la racionalidad evaluadora. Aquí lo raro (queer) ${ }^{3}$ no se entiende como identidad sino más bien como una conjunción de pensamiento, lenguaje y acción que se mueve en direcciones contrarias a las explícitamente reconocidas; pues aun cuando parezca que el reconocimiento es la condición previa de toda vida vivible también sirve para demostrar que sus propios elementos (como el examen público, la vigilancia y la normalización, de los cuales lo extraño -o queer- escapa) muestran los términos fuera de los cuales también se puede llevar una vida vivible

\footnotetext{
${ }^{3}$ El término queer no alude a la identidad de una persona, sino a su alianza y que, por su propia significación como algo anómalo, peculiar, es una palabra que podemos aplicar cuando establecemos alianzas incómodas o impredecibles en la lucha por la justicia social, política y económica (Butler 75).
} 
(Butler 67). Como cualquiera es portador de alguna "rareza", podríamos decir que es lo que nos posibilita escapar del asecho de una norma. Quizá también es lo que nos posibilita relaciones de alteridad con otros y con el mundo, aunque poco transparentes o carentes de nitidez por la opacidad radical que nos caracteriza. Tal vez es lo que nos permite descansar ante el cansancio del exceso de comprensión o de coherencia que se suele demandar a un sujeto que no le queda más que su andar en busca de un lenguaje común que se ha perdido.

Por un amigo francófilo sabemos que en francés antiguo «erre» designa la manera de avanzar y, en el vocabulario marítimo, refiere a la velocidad adquirida por un barco sobre el que no actúa ningún propulsor. Así también las palabras área (aire), aire (air) y era (ère) se dejan oír en erre. Si, como diría Nietzsche, la verdad no es nada más que una serie de errores conectados entre sí de alguna manera, la verdadera educación sería una que dé lugar, área, aire, tiempo, al error como única manera de avanzar en algún sentido sin que ningún objetivo predefinido sea el propulsor; como en una conversación al respecto dijo Butler: "Comete tu error y encuéntralo magnífico", se trata de pensar una forma de vivir el error como una forma de aceptar nuestra perspectiva limitada (pues siempre estamos viendo parcialidades), aceptándolo como parte de lo que implica estar vivo, esto es, una manera afirmativa de vivir el error y no marcarlo como falta (Giuliano 187). Asumir pedagógicamente estar parcialmente en lo cierto y parcialmente equivocados, forma parte de nuestra rareza perceptiva que no debería ser motivo de una consideración negativa sino de una afirmación radical.

Da la sensación histórica que cualquier rareza y errancia ha tenido que ser sistemáticamente explicada, justificada, encerrada en alguna lógica que la asimile a un ordenamiento o clasificación que no nos inquiete. Esto ha producido normalidades, efectos de las normas, que han hecho del sujeto, junto a las rarezas y las errancias, un mero objeto a evaluar. Como si todo ya estuviera dicho por la regla o la norma (y sus silencios) y nada por su excepción. Aunque la vida, como la educación, persiste y resiste con su carácter de ensayo, cuya invención e improvisación nos (ex)pone en los márgenes, no se trata de adquirir competencias o conocimientos más o menos escolarizados, sino de un movimiento que provoca el deseo de seguir pensando y sintiendo para hacerlo de otra manera. Como la instalación de una inquietud que invita a viajar por revisar eso que estamos siendo, diciendo, sintiendo, pensando y haciendo en el tiempo de un ejercicio sin demasiados 
asideros ni puntos fijos, que mueve palabras, nociones $u$ objetos de $s u$ lugar acostumbrado.

Educar, entonces, es también hacer lugar para lo que no está programado ni previsto, para la palabra que no demanda la violencia de la comprensión sino el abandono de esta pretensión. Porque se trata de una relación de bienvenida, no recíproca ni contractual ni de equivalencias, no legible sino ambigua, no transparente sino ambivalente. Así, educar no es colonizar con ciertos saberes, sino conversar sin dictado ni dictaminación, incluso, sin pretensiones de comunicación. No hay plan, como en una loca historia de amor, el roce no es mera influencia. Entre la espera y lo que sucede se abre un abismo: en la ignorancia del dónde vamos a llegar se juega todo saber en reserva. Lo imprevisible, en afectos y efectos, se cristaliza en un vínculo entre singularidades de tiempos distintos que conviven en medio de un encuentro inédito. Por esto, la educación está fuera de toda medida: es lo que pulveriza todo cálculo y toda aritmética.

\section{Telón: arrojar la piedra y esconder la mano. Trazos sobre Stoner}

Mucho se ha escrito en filosofía, incluso en educación, sobre la cuestión del don, del regalo, del dar sin espera... Pero hay, en esa cantera de sabiduría que suelen alojar los refranes populares, una dimensión afirmativa quizá olvidada o pasada por alto en relación al dicho popular "arrojar la piedra y esconder la mano". Si bien este suele usarse a modo juzgador o en tono de reproche, tal vez pueda pensarse que hay toda una gestualidad ético-política en ese movimiento. No solo se arrojan piedras en las manifestaciones y se esconde la mano para que la policía no nos identifique; también se arrojan libros como piedras (quizá filosofales) que nos golpean y nos dotan de transformaciones que sin ellos no hubiésemos conocido: en particular en la educación, la mano de esas o esos docentes provocadores de lectura suele (incluso necesita muchas veces) esconderse para que cada uno/a se atreva a realizar su propia aventura. No se trata de adquirir un determinado aprendizaje, sino de comenzar cierta búsqueda. El golpe de un texto puede producir un desgarramiento, incluso una herida incurable, cierto dolor también, pero, cual piedra filosofal que nos toca y nos convida de su toque de inmortalidad, de contemporaneidad, de su belleza, tal vez aporte algo más de reflejo a nuestra opacidad constitutiva e incorregible. Algo de esto podría notarse en la novela Stoner de John Williams: 
Un profesor convida un soneto de Shakespeare a sus estudiantes, le pregunta a uno de ellos qué quiere decir. Repitió el fragmento de memoria ante el silencio plano del aula y del estudiante increpado en particular: "Esto percibes, lo que hace tu amor más fuerte, amar bien lo que debes abandonar pronto." La interpelación subsiguiente, da qué pensar: "Shakespeare le habla a través de trescientos años, señor... ¿le escucha?" (Williams 17).

Así comienza la historia de un hijo de granjeros pobres que va a la universidad a estudiar agronomía con la idea de contribuir al desarrollo de la economía familiar, y, por los avatares propios de las a-signaturas, termina por convertirse en profesor de literatura.

Cuando daba clases, a veces, se encontraba tan abstraído en su asignatura que se olvidaba de sus limitaciones, de sí mismo, hasta de sus estudiantes. El entusiasmo lo llevaba del tartamudeo a la gesticulación que le hacía ignorar los apuntes que guiaban sus discursos. El asomo de un amor vacilante a la literatura, al lenguaje, al misterio de la mente y el corazón que se manifiesta en la extraña combinación de letras y palabras, le animaba a hacer aquello que nunca le habían mandado: devenir profesor, como alguien a quien el libro le dice una verdad y a quien se le concede una dignidad artística; un conocimiento que no podía expresar pero que le había cambiado. Como un misterio que no se deja narrar, enseñar podría ser aquí ese ejercicio literario que arroja un profundo velo insondable ante el cual solo podemos entusiasmarnos, sin poder evitarlo. Alzar ese velo por descubrir lo inefable o alcanzar lo inalcanzable no haría más que mostrar al más fuerte como un débil enclenque. Pero no tardaría en darse cuenta que la cara oculta del profesor tiene forma de examen como una experiencia en la que no se puede evitar el dolor ya que se monta sobre normas inflexibles. Este docente prefería preguntar lo menos posible e incluso retrasarse a la hora de llegar a un comité evaluador o a una mesa examinadora para estar allí lo menos posible. La (trans)formación es cuestión de intensidad y turbulencia, la novela enseña que hay que afrontar los estudios como si fueran la vida misma y no un medio específico para un fin concreto.

En su tierna juventud, Stoner había pensado en el amor como en una manera de existir absoluta a la que podría acceder si era afortunado; en su madurez había decidido que era el cielo de una religión falsa hacia el que se debía mirar con sosegado descreimiento, benévolo y 
crónico desprecio o vergonzante nostalgia. A su mediana edad, se daba cuenta que ni se trataba de un estado de gracia ni de una ilusión: lo veía como un estado de conversión, una condición inventada y modificada, minuto a minuto y día a día, por la voluntad y la inteligencia del corazón (Cualquiera podría sentirse tentado a reemplazar la palabra amor por la palabra educación y decir que se trata de una pequeña historia de ella).

Como encontrarse con la publicación del libro de un viejo amor y que en su dedicatoria estén tus iniciales, nubla los ojos e inmoviliza sin poder soltar el libro hasta intentar leerlo entero. Encontrarse en una lectura, traslúcida en la escritura, la maravilla de contemplar a alguien a la hora que se desee. Se siente cerca, como si las manos al tocar el libro tocaran a la persona que lo escribió, como en aquellas noches de invierno.

El sentimiento de pérdida se reabsorbe, afluye, se deja llevar por la corriente, más allá del control de la voluntad, no queriendo salvarse de algo imposible de superar. Bajo la confusión, la indiferencia, el olvido, ahí estaba. El amor, intenso y fijo, siempre había estado ahí. En su juventud lo había dado sin pensar, al conocimiento, a los días tontos y ciegos de cortejo, a su amante como si nunca lo hubiese hecho. Lo había ido dando, de manera extraña, en cada momento de su vida y quizás lo había dado más cuando no era consciente de estar dándolo. No se trataba de una pasión ni de la mente ni de la carne, era más bien una fuerza que comprendía a ambas; como si fuese, más que un asunto de amor, su sustancia específica. A una mujer o un poema, simplemente decía: “¡Mira! Estoy vivo." Una vez más: la vida, como ensayo, con su margen de error constitutivo.

Que nos concedan entonces alguna sabiduría, así al cabo de largos años encontramos con calma otra ignorancia. ¿A cuántos amores hemos renunciado o hemos dejado marchar en el caos de la potencialidad? Esta es toda una definición de educación, aún por seguir escribiéndose. 


\section{Bibliografía}

Butler Judith y Laclau Ernesto. Los usos de la igualdad. Debate feminista. 19, 1999: 115-139.

Butler Judith. Cuerpos aliados y lucha politica. Hacia una teoría performativa de la asamblea. Buenos Aires: Paidós, 2017.

Giuliano, Facundo. Rebeliones éticas, palabras comunes. Conversaciones (filosóficas, politicas, educativas) con Judith Butler, Raúl Fornet-Betancourt, Walter Mignolo, Jacques Rancière, Slavoj Žižek. Buenos Aires: Miño y Dávila, 2017.

Giuliano, Facundo. Desnudar la razón evaluadora. Elementos para un combate filosófico-educativo. Pensamiento. Revista de Investigación e Información Filosófica, 2019, vol. 75, no 287, p. 1451-1474.

Jitrik Noé. Verde es toda teoría: literatura, semiótica, psicoanálisis, lingüística. Buenos Aires: Liber, 2010.

Skliar Carlos. Pedagogías de las diferencias: notas, fragmentos, incertidumbres. Buenos Aires: Noveduc, 2017.

Williams Jhon Edward. Stoner. Tenerife: Ediciones de Baile del Sol, 2016.

\section{Como citar:}

Giuliano Facundo. “¿Realidad de la ficción evaluadora o ficción de la realidad evaluadora? Apuntes literarios y cinematográficos para una crítica de la razón evaluadora". Discusiones Filosóficas. Jul.- Dic. 20 (35), 2019: 149-165. DOI: 10.17151/difil.2019.20.35.9. 